\title{
Effect of microcrystallites formed by deformation on the growth and orientation of grains during recrystallization of iron
}

\author{
L. M. Voronova ${ }^{\dagger}$ M. V. Degtyarev, T. I. Chashchukhina, D. V. Shinyavskii, T. M. Gapontseva \\ †highpress@imp.uran.ru
}

\author{
M. N. Mikheev Institute of Metal Physics, Ural Branch of RAS, ul. S. Kovalevskoi, 18, Yekaterinburg, 620990, Russia
}

Changes of an ultradispersed structure in deformed iron after annealing have been studied. Ultradispersed structures of two different types, cellular and submicrocrystalline (SMC) ones, have been formed in iron by high pressure torsion deformation. The effect of the deformation structure type on the temperature of recrystallization onset, the size of recrystallized grains, and the recrystallization texture has been explored. A comparison of recrystallization of the initial cellular and SMC structures should be made to determine the role of microcrystallites. The recrystallization temperature of iron with an SMC structure is 200 to $250^{\circ} \mathrm{C}$ lower than that of iron with a cellular structure because of the presence of microcrystallites, which are ready recrystallization nuclei. The recrystallization (annealing at $750^{\circ} \mathrm{C}, 1 \mathrm{~h}$ ) of the cellular structure results in the formation of a coarse-grained structure with an average recrystallized grain size that is by an order of magnitude larger than that after the same annealing of the SMC structure (5 and $180 \mu \mathrm{m}$, respectively). The significantly different feature of the SMC structure in contrast to the cellular one is the annealing-assisted formation of a $\langle 110\rangle$ recrystallization texture in it, whereas the annealing of iron with the cellular structure does not cause the formation of a recrystallization macrotexture. An increase in the sharpness of the recrystallization texture correlates with a decrease in the average grain-boundary misorientation angle.

Keywords: submicrocrystalline structure, recrystallization, texture.

\section{Introduction}

The formation of a structure providing desired properties is often associated with the transition of a material into a thermodynamically nonequilibrium structural state. A subsequent treatment and a use of the material will cause changes, reducing the free energy of the system. If the formed structure is optimum, these changes will deteriorate properties of the material. Therefore, the problem of the thermal stability of a formed microstructure is of importance. Severe plastic deformation results in the formation of an ultradispersed structure with a high density of defects. This structure possesses a large stored energy and is metastable $[1-4]$.

The structure of iron during severe plastic deformation, in particular, in Bridgman anvils, develops stage-by-stage $[5,6]$. Firstly, the structure of a cellular type is formed; then individual microcrystallites (regions surrounded by highangle boundaries [7]) appear with increasing true strain, resulting in the formation of a mixed structure; and finally, the material transits into a submicrocrystalline state. The sizes of structural elements are from a few tenths to hundredths of a micron, that is, all types of structure belong to the submicron scale, but differ in types of boundaries and texture.

The evolution of the structure and the mechanical properties of both pure iron and armco iron during shear under pressure have been studied in many works [5, 8-12]. But only in a few of them the change of the crystallographic texture is analyzed $[5,10,12]$. According to X-ray studies in pure iron, most of the elements at the stage of the mixed structure has been established to possess an $\{101\}$ orientation, whereas the material at the stage of the SMC structure transits into a textureless state [5]. Data received by means of electron back-scatter diffraction (EBSD) give an evidence that the final texture obtained by HPT is $\{110\}$ being parallel to the disc [12].

The structure and texture formed during deformation is known to have a considerable influence on the development of recrystallization [2]. The microcrystallites, which are ready nuclei, ensure recrystallization of an SMC structure without incubation period and at rather low temperatures (less than $\left.0.35 T_{\mathrm{m}}\right)[13-15]$.

However, the effect of annealing on the texture of iron produced by severe plastic deformation was not investigated. In $[13,14]$, for SMC Armco-iron, two temperature intervals were established at which slow and rapid grain growth occurs. At the stage of slow grain growth, the effect of triple junction drag on grain boundaries motion plays an important role [14]. It is known [2] that the presence of a texture can also suppresses the growth of grain. Therefore, an analysis of texture evolution during annealing of SMC iron is important for studying its thermal stability. Similar investigations of fcc metals are currently underway [16], while data for bcc metals are not available in the literature.

A comparison of recrystallization of the initial cellular and SMC structures should be made to determine the features of recrystallization of the SMC structure and the role of microcrystallites in this process. The aim of the work is to study the effect of recrystallization on the parameters of the cellular and the SMC structures in iron (grain size, 
preferential grain orientation, distribution of misorientation angles, mean misorientation angle). Particular attention is paid to the analysis of microtexture formed during annealing.

\section{Methodology}

Iron $(99.97 \% \mathrm{Fe}, 0.003 \% \mathrm{C}$, and $<0.3 \%$ other impurities) prepared by zone melting was used for the investigation. Samples to be deformed were in the shape of disks with a diameter of $5 \mathrm{~mm}$ and a thickness of $0.3 \mathrm{~mm}$. Deformation was performed at a pressure of $6 \mathrm{GPa}$ in Bridgman anvils. The structure of a cellular type was obtained by upsetting in the anvils. The true strain determined from the change in the sample thickness is $e=1.4$. An SMC structure formed after 5 revolutions of the anvil during high pressure torsion. The true strain was calculated taking into account the shear components of the deformation and upsetting, which depended on a distance to the sample center. The calculation method is described in detail in [5]. The true strain at a distance of $1.5 \mathrm{~mm}$ from the center of a sample was $e=8$. The deformed samples were annealed at temperatures of 350 to $750^{\circ} \mathrm{C}$ for $1 \mathrm{~h}$. The annealing was carried out in a vacuum of $10^{-2} \mathrm{~Pa}$ to prevent oxidation of the samples. The iron structure after deformation and annealing was examined by scanning and transmission electron microscopy (SEM and TEM) using QUANTA 200 Philips, and JEM 200CX, respectively. The size of recrystallized grains was determined by an intercept method using SEM data, and by direct measuring using TEM data. The orientation of recrystallized grains was estimated from electron back scattering diffraction (EBSD) data.

\section{Results and discussion}

Fig. 1 demonstrates the microstructure of the samples after deformation. Transmission electron microscopy shows both individual dislocations and pile-ups of dislocations inside
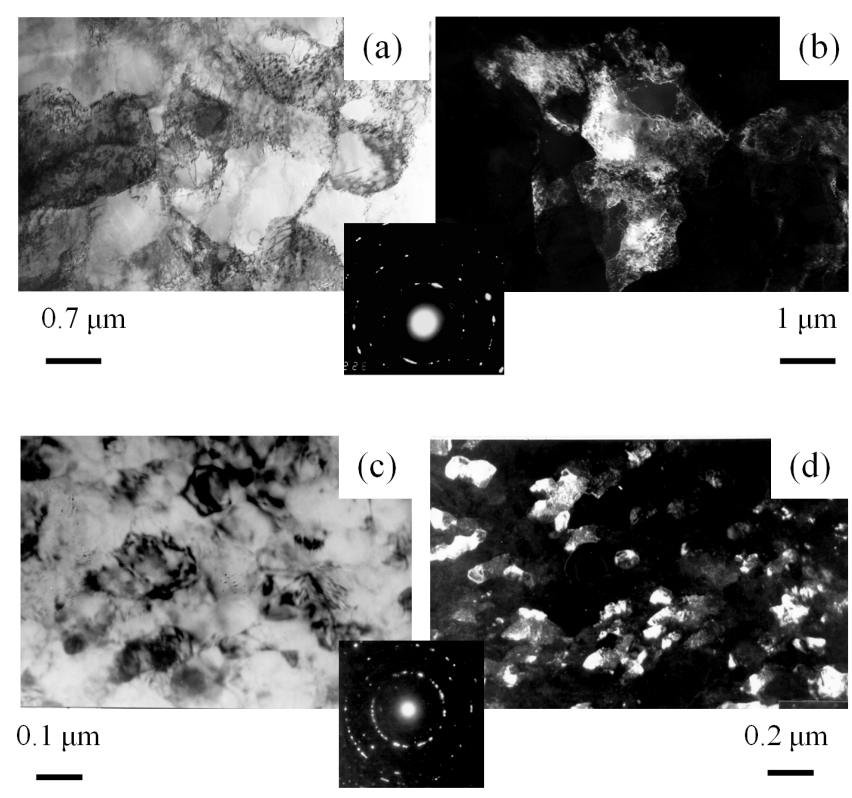

Fig. 1. (a, b) Cellular and (c, d) SMC structures in iron: (a, c) brightfield image and (b, d) dark-field image in a (110) reflection. cells with low-angle boundaries in the cellular structure. Angle misorientation changes gradually from one cell to another, resulting in a nonuniform dark-field contrast. The electron diffraction pattern is characterized by azimuthally spread reflections (Figs. 1a, 1b) due to a gradual increase in the misorientation angle between one cell and the other. The cell size varies in the wide range, with an average size of $0.9 \mu \mathrm{m}$. The SMC structure (Fig. 1c, 1d) is characterized by high size uniformity and the average microcrystallite size of $0.15 \mu \mathrm{m}$. Extinction contours are observed in the volume of microcrystallites, which testify to the elastic deformation of the crystal lattice. A dark-field contrast at microcrystallite boundaries sharply changes, which indicates a discrete change in the misorientation angle at a boundary. Reflections in the electron diffraction pattern are point in shape and they form a nearly ring diffraction pattern.

In iron with the cellular structure, recrystallization begins at $450^{\circ} \mathrm{C}$. Annealing for $1 \mathrm{~h}$ results in the recrystallization of about $70 \%$ of material. At this temperature, thermallyactivated formation of recrystallization centers takes place, which is in a good agreement with literature data [17]. The average recrystallized grain size is $15 \mu \mathrm{m}$ (Table 1), whereas some grains achieve $75 \mu \mathrm{m}$ in size (Fig. 2a). The arrows on the Fig. 2a show the regions, which contain mainly lowangle boundaries, according to EBSD data. Obviously, this is a subgrain structure formed during recovery. A rather large fraction of low-angle boundaries in the subgrain structure determines the average grain-boundary misorientation angle $\left(33^{\circ}\right)$ which is lower than that in the random ensemble of grains $\left(40^{\circ}\right)$ [18]. An increase in the annealing temperature causes a growth of the average grain size together with the average grain-boundary angle, the last reaches the value of $39^{\circ}$ (Table 1). Direct pole figures obtained by EBSD method are shown in Fig. 3. The figure suggests no regularity of a texture change after annealing: a weakly pronounced $<001>$ axial texture is formed at 450 and $650^{\circ} \mathrm{C}$, whereas there is no texture after annealing at $550^{\circ} \mathrm{C}$, and a $<111>$ texture is
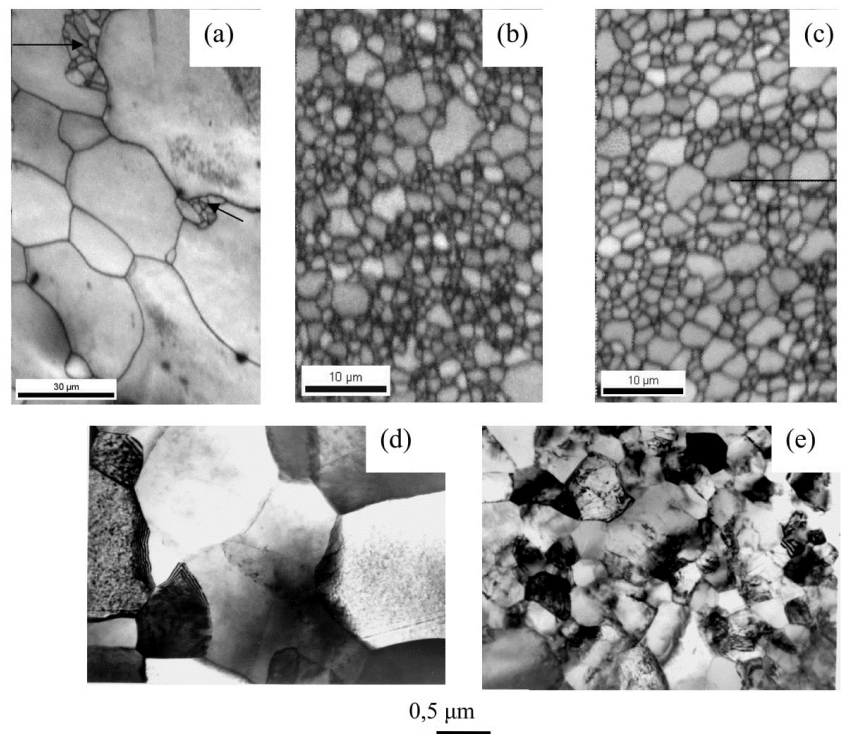

Fig. 2. Iron microstructure after deformation and annealing: (a) cellular structure after annealing at $450^{\circ} \mathrm{C}$ for $1 \mathrm{~h}$; (b, d) SMC structure after annealing at $350^{\circ} \mathrm{C}$ for $1 \mathrm{~h}$; (c, e) SMC structure after annealing at $450^{\circ} \mathrm{C}$ for $1 \mathrm{~h}$; (a-c) SEM; and (d, e) TEM. 


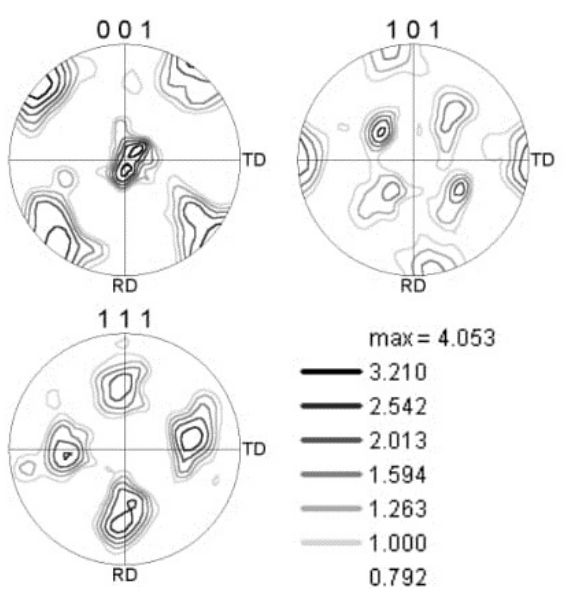

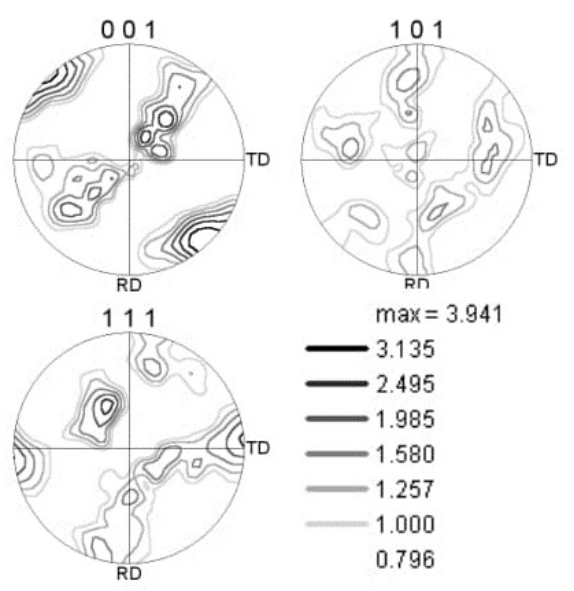

b
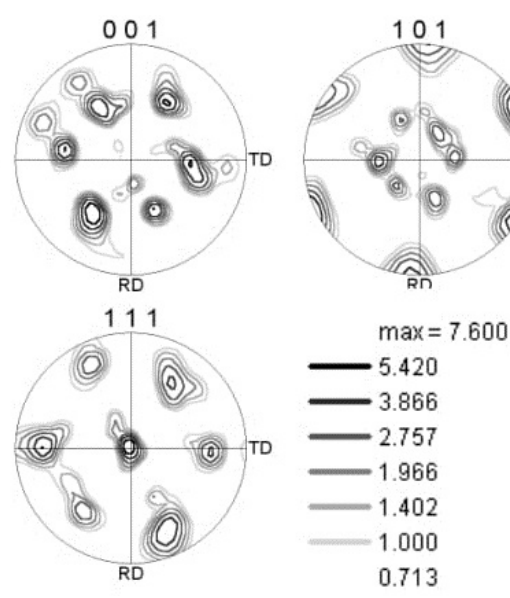

C

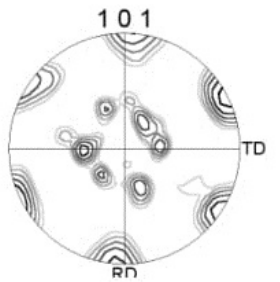

$\max =7.600$

Fig. 3. Pole figures constructed by the EBSD analysis of the cellular iron structure after annealing at (a) $450^{\circ} \mathrm{C}$ for $1 \mathrm{~h}$; (b) $550^{\circ} \mathrm{C}$ for $1 \mathrm{~h}$; and (c) $750^{\circ} \mathrm{C}$ for $1 \mathrm{~h}$.

Table 1. The parameters of the structure of iron after deformation and annealing, according to different methods of structural studying.

\begin{tabular}{|c|c|c|c|c|c|c|}
\hline \multirow{2}{*}{$\begin{array}{c}\text { Structure } \\
\text { type }\end{array}$} & \multirow{2}{*}{$\begin{array}{c}T \text { an., } \\
{ }^{\circ} \mathrm{C}\end{array}$} & \multicolumn{2}{|c|}{ TEM } & \multicolumn{3}{c|}{ SEM } \\
\cline { 3 - 7 } & $d, \mu \mathrm{m}$ & $K$ & $d, \mu \mathrm{m}$ & $K$ & $\Theta,{ }^{\circ}$ \\
\hline \multirow{4}{*}{ SMC } & 350 & 1.3 & 0.6 & 1.0 & 0.9 & 35 \\
\cline { 2 - 7 } & 450 & 0.5 & 0.6 & 1.2 & 0.8 & 36 \\
\cline { 2 - 7 } & 650 & - & - & 2 & 1.5 & 30 \\
\cline { 2 - 7 } & 750 & - & - & 5 & 1.2 & 25 \\
\hline \multirow{4}{*}{ cellular } & 450 & - & - & 15 & 1.4 & 33 \\
\cline { 2 - 7 } & 550 & - & - & 70 & 1.1 & 37 \\
\cline { 2 - 7 } & 650 & - & - & 120 & 1.1 & 33 \\
\cline { 2 - 7 } & 750 & - & - & 180 & 1.5 & 39 \\
\hline
\end{tabular}

observed after annealing at $750^{\circ} \mathrm{C}$. The maximum pole density is less or equal to 8 rel. units. It should be noted that this method provides the information from a quite local region, therefore, no regularity of the texture change upon annealing indicates that there is no a recrystallization macrotexture over the entire sample.

In iron with an SMC structure, recrystallization begins at a temperature well below $450^{\circ} \mathrm{C}$. In [19] it was shown that the deformation-induced formation of ready recrystallization nuclei (microcrystallites) allows obtaining a completely recrystallized structure in iron at $200^{\circ} \mathrm{C}$, but prolonged periods of annealing time are required to complete the recrystallization. Figs. $2 \mathrm{~b}$ and $2 \mathrm{~d}$ demonstrate that annealing at $350^{\circ} \mathrm{C}$ for $1 \mathrm{~h}$ results in the formation of a uniform-in-size grain structure. The TEM examination shows that annealing at $450^{\circ} \mathrm{C}$ for $1 \mathrm{~h}$ causes the formation of grains with a large number of defects, in their volume, and fine recrystallization nuclei (Fig. 2e) which were not observed after 1-h annealing at $350^{\circ} \mathrm{C}$ (Fig. 2d). These observations allow us to conclude that the annealing of iron with an SMC structure at $450^{\circ} \mathrm{C}$ leads to thermally-activated formation of new recrystallization centers. As a result, the average grain size becomes half in size (Table 1). These recrystallization nuclei are not observed by the SEM method, therefore at this scale level the structure after annealing at 350 and $450^{\circ} \mathrm{C}$ differs little (Figs. 2b, 2c, Table 1). The average grain size is about $1 \mu \mathrm{m}$.

Annealing of iron with an SMC structure in the temperature range 550 to $750^{\circ} \mathrm{C}$ leads to an increase in the
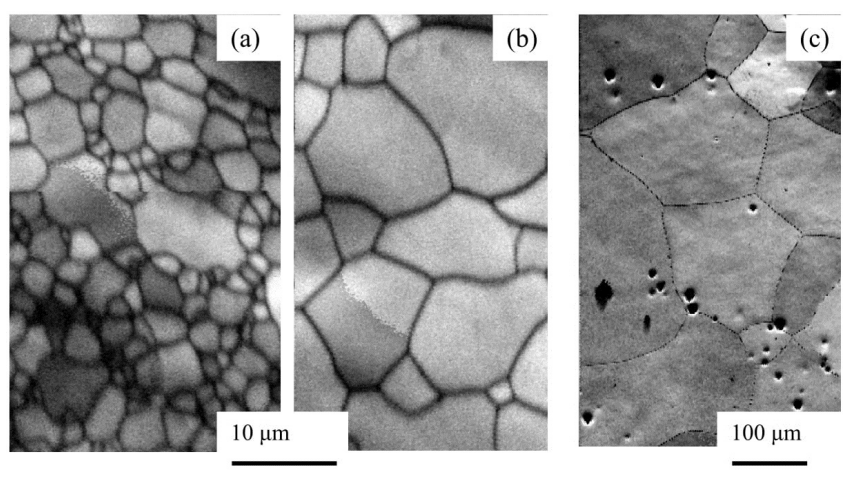

Fig. 4. SEM images of the (a, b) SMC and (c) cellular iron structures after annealing at (a) $650^{\circ} \mathrm{C}$ and $(\mathrm{b}, \mathrm{c}) 750^{\circ} \mathrm{C}$.

average size of the recrystallized grain to $5 \mu \mathrm{m}$ (Table 1, Figs. 4a, 4b). According to SEM, the variation coefficient of the linear grain sizes increases sharply with increasing annealing temperature. It should be noted that in this case the sizes were obtained using EBSD analysis, which takes into account the sizes of grains and subgrains with small misorientation angles. Low-angle boundaries are observed inside the recrystallized grains after annealing at temperatures of 650 to $750^{\circ} \mathrm{C}$, which can decrease the average misorientation angle $\Theta$ between the structural elements (Table 1).

It should be noted that a result of the recrystallization of the cellular structure in this temperature range is the formation of a coarse-grained structure, the average grain size of which increases to $180 \mu \mathrm{m}$ after annealing at $750^{\circ} \mathrm{C}$ (Fig. 4c, Table 1). This means that the recrystallized grain is an order of magnitude coarser than that of the annealed SMC structure, under the same annealing conditions.

In contrast to the cellular structure, a distinct feature of the SMC structure is the annealing-induced formation of $\langle 110\rangle$ texture. The EBSD analysis showed that after annealing at $350^{\circ} \mathrm{C}$, the fraction of the area occupied by grains with an orientation of the (110) type is $<40 \%$. After annealing at $750^{\circ} \mathrm{C}$, the large fraction of the recrystallized grains $(\sim 80 \%)$ has this orientation. The pole figures shown in Fig. 5 demonstrate an increase in the texture sharpness when the annealing temperature is increased. As a result, the average misorientation angle decreases with increasing annealing temperature (Table 1 ). 

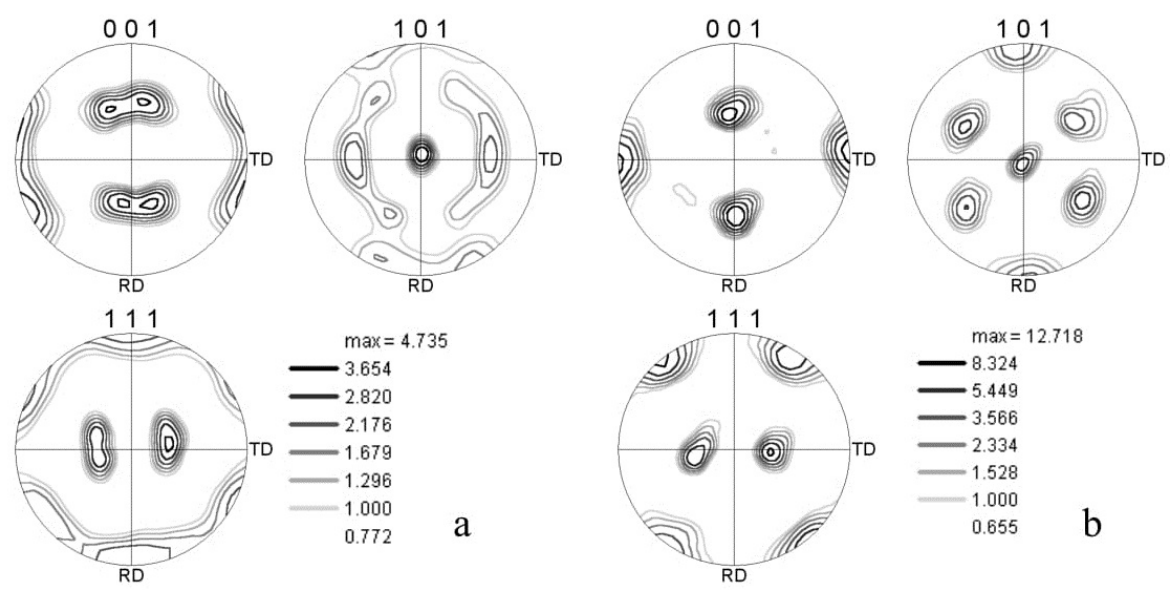

Fig. 5. Pole figures constructed by the EBSD analysis of the SMC iron structure after annealing at (a) $350^{\circ} \mathrm{C}$ and (b) $650^{\circ} \mathrm{C}$.

\section{Conclusions}

1. The recrystallization annealing of deformed iron allows one to reveal significant differences in the behavior of ultradispersed structures of various types, namely, a cellular structure with small-angle gradual misorientations and an SMC structure with discrete high-angle misorientations of microcrystallites. Nevertheless, both structures had no preferential orientation.

2. The recrystallization temperature of iron with an SMC structure is 200 to $250^{\circ} \mathrm{C}$ lower than that of iron with a cellular structure because of microcrystallites, which are ready recrystallization nuclei. After annealing of the SMC structure at $750^{\circ} \mathrm{C}$ for $1 \mathrm{~h}$, the average recrystallized grain size was $5 \mu \mathrm{m}$, whereas that of the cellular structure was $180 \mu \mathrm{m}$.

3. A significantly different feature of the SMC structure in contrast to the cellular one is the annealingassisted formation of a $<110>$ recrystallization texture in it, whereas the annealing of iron with the cellular structure does not cause the formation of a recrystallization macrotexture. An increase in the sharpness of the recrystallization texture correlates with a decrease in the average grain-boundary misorientation angle.

Acknowledgments. This work was partly supported by the Russian Foundation for Basic Research, project no. 15-03-00909-a. The electron microscopic studies were performed at the Center of the Collaborative Access "Test Center of Nanotechnologies and Advanced Materials," Institute of Metal Physics, Ural Branch, Russian Academy of Sciences.

\section{References}

1. H.W. Zhang, X. Huang, R. Pippan, N. Hansen. Acta Materialia. 58, 1698 (2010).

2. F.J. Humphreys, M. Hatherly. Recrystallization and related annealing phenomena. Amsterdam; Boston: Elsevier Ltd. (2004). 628p.
3. I.A. Ditenberg, E.A. Korznikova, A.N. Tyumentsev, D. Setman, M. Kerber. Letters on materials. 4 (2), 100 - 103 (2014). DOI: 10.22226/2410-3535-2014-2-100-103

4. R.Z. Valiev, I. V. Alexandrov. Nanostructured materials obtained by severe plastic deformation. M.: Logos. (2000) 272 p. (in Russian) [Валиев Р.3., Александров И. В. Нан оструктурные материалы, полученные интенсивной пластической деформацией. М.: Логос. 2000. 272 с.]

5. M. V. Degtyarev, T.I. Chashchukhina, L.M. Voronova, A. M. Patselov, V. P. Pilyugin. Acta Mater. 55, 6039 (2007).

6. E. A. Korznikova. Letters on materials. 2 (2), 67-70 (2012). DOI: 10.22226/2410-3535-2012-2-67-70

7. N. A. Smirnova, V. I. Levit, Pilyugin V.P., R. I. Kuznetsov, L.S. Davydova, V.A. Sazonova, Phys. Met. Metallogr. 61 (6), 127 (1986).

8. R.Z. Valiev, Y.V. Ivanisenko, E. F. Rauch, B. Baudelet. Acta Mater. 44, 4705 (1996).

9. Y. Todaka, M. Yoshii, M. Umemoto, C. Wang, K. Tsuchiya. Mater. Sci. Forum 584-586, 597 (2008).

10. S. Descartes, C. Desrayaud, E. F. Rauch. Mater. Sci. Eng. A 528, 3666 (2011).

11. Y. V. Ivanisenko, R. Z. Valiev, H.-J. Fecht. Mater. Sci. Eng. A 390, 159 (2005).

12. A. Hosokawa, S. Ii, K. Tsuchiya. Materials Transactions. 55 (7), 1097 (2014).

13. Yu. V. Ivanisenko, A.A. Sirenko, A.V. Korznikov. Phys. Met. Metallogr. 87 (4), 329 (1999).

14. A. N. Aleshin, A. M. Arsenkin, S. V. Dobatkin. Mater. Sci. Forum. 550, 465 (2007).

15. L. M. Voronova, M. V. Degtyarev, T.I. Chashchukhina. Phys. Met. Metallogr. 104, 262 (2007).

16. P. Ghosh,, O. Renk, R. Pippan. Mater. Sci. Eng. A. 684, 101 (2017).

17. S.S. Gorelik. Recrystallization of Metals and Alloys., Moscow, Metallurgiya. (1978) 568p. (in Russian).

18. F. J. J. Humphreys. Mater. Sci. 36, 3833 (2001).

19. M.V. Degtyarev, L.M. Voronova, V.V. Gubernatorov, T. I. Chashchukhina. Dokl. Phys. 47, 647 (2002). 